\section{Report of All \\ India Institutes of Medical Sciences Neuroanesthesia Update 2014, New Delhi, India}

\author{
Gyaninder P Singh, Mihir P Pandia, \\ Keshav Goyal
}

The All India Institutes of Medical Sciences (AIIMS) Neuroanesthesia Update 2014 was organized by the department of Neuroanesthesiology and Critical Care, AIIMS, New Delhi on 30-31 August 2014. After the overwhelming response and success of the first AIIMS Neuroanesthesia update held in Oct 2013 which was liked and appreciated by most of the delegates and who demanded to make it an annual event, this second update was once again organised under the stewardship of Prof. Parmod K Bithal. The event turned out to be a great platform for the participants especially the young anesthesiologists for sharing knowledge and discuss the recent advances and developments in Neuroanesthesiology and Neurocritical Care. More than 160 delegates gathered during the event and actively participated in the discussion.

The update started with a workshop which included the live demonstration of three important and challenging neurosurgical cases. There was a direct transmission (audio-visual relay) of cases from AIIMS Neurosurgery operation rooms and the audience were able to directly interact and discuss the management of these cases with the experts managing the cases in the operation theatre. The first case was an infra-tentorial tumor operated in sitting position and the expert for this case was Prof. H H Dash (Director, Anaesthesia and Pain Management, Fortis Memorial Research Institute, Gurgaon). The second case was an aneurysm surgery which was managed by Prof. P K Bithal
(Head, Department of Neuroanesthesiology, AIIMS, New Delhi) while the experts for the third case (Pituitary tumor operated endoscopically) were Prof. V K Grover [Head, Department of Anesthesiology, Postgraduate Institute of Medical Education and Research (PGIMER), Chandigarh] along with Dr. M Radhakrishnan [National Institute of Mental Health and Neuro Sciences (NIHMANS), Bengaluru]. Dr Hemant (PGIMER, Chandigarh), Dr Ashish, Dr Keshav, Dr Surya, and Dr Charu (AIIMS, New Delhi) moderated the workshop and facilitated the discussion between the audience and experts. Complete anesthetic management including preoperative preparation, intraoperative concerns, and management and post-operative plan was discussed for each case. Besides this, Dr Navdeep (AIIMS, New Delhi) demonstrated the use of cardiac output monitor and its applications during the intraoperative anesthetic management of neurosurgical cases.

Post-lunch session started with Neuroanesthesia Symposium which had three sessions. The first session was chaired by Prof. Amna Goswami (Kolkata), Dr. Anil Parakh (Mumbai), and Dr. Devendra Gupta (Lucknow). There were three lectures in this session on very important and relevant topics in present day scenario. Dr. Hemanshu Prabhakar (New Delhi) talked on "How to select a research topic in Neuroanesthesia?" Dr. Zulfiqar Ali (Srinagar) discussed the "Basic radiology and angiography for Neuroanesthesiologists" while Dr. Gyaninder Pal Singh (New Delhi) highlighted on the "Biomarkers of interest for neuro research." The second session again had three lectures. The first lecture was by Dr. Girija Prasad Rath (New Delhi) who talked on "Recent advances in head injury management." The second lecture on "Blood transfusion in patients with injured brain" was delivered by Dr. Indranil Ghosh (Kolkata) and third lecture on Mechanical Ventilation in neuro patients" by Dr. M. Radhakrishnan (Bengaluru). The Chairpersons for this session were Prof. V K Grover (Chandigarh), Prof. L D Mishra (Varanasi), and Prof. Monika Tandon (New Delhi).

The post-lunch session was followed by a formal inaguration ceremony. Prof. M C Misra (Director, AIIMS, New Delhi) was the chief guest and presided

Department of Neuroanaesthesiology, All India Institute of Medical Sciences, New Delhi, India

Address for correspondence:

Dr. Mihir Prakash Pandia, Department of Neuroanaesthesiology, All India Institute of Medical Sciences, Room No. 709 ( $7^{\text {th }}$ floor), Neurosciences Centre, New Delhi - 110 029, India. E-mail: pandiamihir@gmail.com 
over the meeting. The ceremony was conducted in presence of several dignitaries on the dais Prof. S S Saini (Director, Neuroanesthesia, Paras Hospital, Gurgaon), Prof. H L Kaul (former Head, Department of Anesthesiology, AIIMS, New Delhi), Prof. H H Dash (Director, Anesthesia and Pain Management, Fortis Memorial Research Institute, Gurgaon), Prof. P K Bithal (Organising Chairman, AIIMS Neuroanesthesia Update 2014), and Dr. M P Pandia (Organising Secretary, AIIMS Neuroanesthesia Update 2014). After the lamp lightning ceremony, the gathering was addressed by the dignitaries who shared their experiences in Neuroanesthesia and also encouraged the young anesthesiologists to achieve their best in this very fascinating branch of medicine. The event was followed by high tea.

The third and last session of the day was an "Interactive case discussions." Dr. Gyaninder Pal Singh and Dr. Keshav Goyal (New Delhi) moderated the discussion of three important case scenarios. The cases discussed included "Management of a patient who had sudden deterioration in consciousness two days after clipping of anterior communicating artery (ACOM) aneurysm", "Anesthetic management of a new born with cleft palate and subdural haematoma who needs urgent craniotomy" and "Anesthetic management of a pregnant patient for spine surgery." There were two experts for each case, Prof. H H Dash (Gurgaon) and Dr Prasanna Bidkar (Puducherry) for first case, Prof. Mary Abraham (Noida) and Dr. Renu Bala (Rohtak) for second case, and Prof. Monica Tandon (New Delhi) and Dr. Manish Marda (Noida) for the third case. Audience actively participated in the discussion and final comments were made by the respective experts for the case. The day ended with light music and dinner.

The second day began with a lecture by Prof. P K Bithal (New Delhi) on "Optimal use of anesthetic agents in Neuroanesthesia." This was followed by two more lectures on "How best can we monitor the brain in an ICU" by Dr. Keshav Goyal (New Delhi) and "Recent advances in fluid management in Neuroanesthesia" by Prof. L D Mishra (Varanasi). This session was chaired by Prof. Arvind Chaturvedi (New Delhi), Dr. Mukul Jain (New Delhi), and Dr. Sorabh Anand (Gurgaon).

The next session for the day started with the lectures on "Emergence in Neuroanesthesia" by Prof. H H Dash (Gurgaon) who highlighted and emphasized the importance of smooth and early emergence in neurosurgical patients. Other lectures included "Assessment of recovery and post operative monitoring after Neurosurgery" by Prof. Pragati Ganjoo (New Delhi), "Recent advances in hyperosmolar therapy" by Dr. Kavita Sandhu, and "Cardiac complications of acute brain injury" by Dr. Nidhi Panda. All the speakers elaborately discussed their topics and highlighted the salient points. Dr. KJ Choudhary (New Delhi) and Dr. Parul Khare (New Delhi) chaired the session. Another session before lunch included two important talks on "Blood pressure management during and after intracranial surgery" by Dr. Virendra Jain (Gurgaon) and "Deep vein thrombosis in neurosurgical patients" by Dr. Prasanna Bidkar (Puducherry). The chairpersons for this session were Dr. RS Chouhan (New Delhi) and Dr. RB Singh (Varanasi).

During the post-lunch session, important issues regarding management of patients in neurointensive care units were discussed. Dr. Ponniah Vanamurthy (Chennai) talked on "Intensive care management of ischemic stroke" and discussed in length about the problems in managing these patients. Dr. Ashish Bindra (New Delhi) discussed the role of "Hypothermia in Neurocritical care practice" while "ICU management of cervical spinal cord injury patients" was discussed by Dr. Niraj Kumar (New Delhi).

The last session was an interactive case discussion moderated by Dr. Ashish Bindra and Dr. Indu Kapoor (New Delhi). There was in depth discussion of three cases with active participation by the delegates. There were two experts for each case who gave final comments and their expert opinion regarding the controversial issues. First case discussed was "ICU management of a patient, three days post extubation following transoral odontoidectomy and posterior fixation with severe respiratory distress" and the experts for the case were Prof. Pragati Ganjoo (New Delhi) and Dr. Richa Aggarwal (New Delhi). The second case was "Anesthetic management of a patient with brain tumor with bad chest who require urgent tumor decompression in sitting position" and the experts were Dr. KJ Choudhury (New Delhi) and Dr. Navdeep Sokhal (New Delhi). The third and final case was "Anesthetic management in a young male with anti-coagulation therapy for chronic atrial fibrillation having altered sensorium and posted for resection of large arteriovenous malformation." Dr. H Sapra (Gurgaon) and Dr. Vasudha Singhal (Gurgaon) were the experts for this case.

The conference concluded with the valedictory function and prize distribution to the residents who actively participated during the interactive case discussions. The delegates came forward to share their experiences and suggestions and congratulated the organisers 
for organising a great academic treat. The organising secretary, on behalf of his team thanked everyone for their active participation during the conference. The delegates cheered and applauded for the host. The event was followed by a high tea.

\begin{tabular}{|l|l|}
\hline \multicolumn{2}{|c|}{ Access this article online } \\
\hline Quick Response Code: & Website: \\
\hline & www.jnaccjournal.org \\
\cline { 2 - 2 } & \\
\hline & \\
\end{tabular}

\section{New features on the journal's website}

\section{Optimized content for mobile and hand-held devices}

HTML pages have been optimized of mobile and other hand-held devices (such as iPad, Kindle, iPod) for faster browsing speed. Click on [Mobile Full text] from Table of Contents page.

This is simple HTML version for faster download on mobiles (if viewed on desktop, it will be automatically redirected to full HTML version)

\section{E-Pub for hand-held devices}

EPUB is an open e-book standard recommended by The International Digital Publishing Forum which is designed for reflowable content i.e. the text display can be optimized for a particular display device.

Click on [EPub] from Table of Contents page.

There are various e-Pub readers such as for Windows: Digital Editions, OS X: Calibre/Bookworm, iPhone/iPod Touch/iPad: Stanza, and Linux: Calibre/Bookworm.

\section{E-Book for desktop}

One can also see the entire issue as printed here in a 'flip book' version on desktops. Links are available from Current Issue as well as Archives pages.

Click on View as eBook 